\title{
Três esquemas analíticos para analisar o tráfico internacional de pessoas: em busca de uma concepção política da violência
}

\author{
Three analytical schemes to analyze international trafficking in people: in search of a political \\ conception of violence
}

Tres esquemas analíticos para analizar la trata internacional de personas: en busca de una concepción política de violencia

Recebido: 14/01/2021 | Revisado: 18/01/2021 | Aceito: 18/01/2021 | Publicado: 21/01/2021

\author{
Vinicius Ferreira Baptista \\ ORCID: https://orcid.org/0000-0002-8717-8332 \\ Universidade Federal Rural do Rio de Janeiro, Brasil \\ E-mail: viniciusferbap@ufrrj.br
}

\begin{abstract}
Resumo
O objetivo deste ensaio é delimitar um esquema analítico sobre o Tráfico Internacional de Pessoas (TIP), considerando suas peculiaridades, em busca de uma concepção sociológica-jurídica que avalie a noção da pessoa traficada e o status da vítima. Metodologicamente, empreendemos estudo de caráter exploratório, afim de alcançar objetivo descritivo, a partir de procedimentos bibliográficos, documentais e estatísticos. Delimitamos, assim a necessidade de articulação de diversos elementos sociais, políticos e econômicos que possam dar conta de um fenômeno multifacetado, econômica sociológica e politicamente que impactam nas formas como o TIP se enraíza na estrutura de um país. Desenvolvemos, portanto, um esquema tripartite conceitual, sociológico-jurídico e político. Os três esquemas podem permitir, em conjunto, uma leitura mais precisa de um crime não pode mais ser lido sob apenas uma lente. Remetemos à ideia de que uma concepção política do Tráfico Internacional de Pessoas demanda uma concepção sociológica que analise as dinâmicas sociais, tendo em vista a garantia de direitos à vítima, afim de que se rompa este crime.
\end{abstract}

Palavras-chave: Tráfico internacional de pessoas; Crimes transnacionais; Teoria política; Violência; Violência política.

\begin{abstract}
The objective of this essay is to delimit an analytical scheme on International Trafficking in Persons (ITP), considering its peculiarities, in search of a sociological and juridical conception that assesses the notion of the trafficked person and the status of the victim. Methodologically, we undertake an exploratory study, in order to achieve a descriptive objective, based on bibliographic, documentary and statistical procedures. Thus, we delimit the need for the articulation of several social, political and economic elements that can account for a multifaceted, economical, sociological and political phenomenon that affect the ways in which ITP takes root in the structure of a country. We therefore developed a conceptual, sociological-legal and political tripartite scheme. The three schemes can allow a more accurate reading of a crime no longer read under just one lens. We refer to the idea that a political conception of International Trafficking in Persons demands a sociological conception that analyzes social dynamics, with a view to guaranteeing the victim's rights, in order to stop this crime.
\end{abstract}

Keywords: International trafficking in persons; Transnational crimes; Political theory; Violence; Political violence.

\section{Resumen}

El objetivo de este ensayo es delimitar un esquema analítico sobre la Trata Internacional de Personas (TIP), considerando sus peculiaridades, en busca de una concepción sociológica y jurídica que evalúe la noción de víctima de trata y la condición de víctima. Metodológicamente, realizamos un estudio exploratorio, con el fin de lograr un objetivo descriptivo, basado en procedimientos bibliográficos, documentales y estadísticos. Delimitamos así la necesidad de articulación de diferentes elementos sociales, políticos y económicos que puedan dar cuenta de un fenómeno multifacético, económico, sociológico y político que incide en las formas en que la TIP se arraiga en la estructura de un país. Por lo tanto, desarrollamos un esquema tripartito conceptual, sociológico-legal y político. Los tres esquemas pueden, juntos, permitir una lectura más precisa de un crimen que ya no se puede leer bajo una sola lente. Nos referimos a la idea de que una concepción política de la Trata Internacional de Personas exige una concepción sociológica que analice las dinámicas sociales, con miras a garantizar los derechos de las víctimas, para detener este crimen.

Palabras clave: Trata internacional de personas; Crímenes transnacionales; Teoría política; Violencia; La violencia política. 


\section{Introdução}

O Tráfico Internacional de Pessoas (TIP) ${ }^{1}$ é considerado um dos crimes associados à globalização de mercados amplificados nas últimas décadas entre 1990 e século XXI: enquanto processos tecnológicos permitiram negociações mais rápidas, tecnologias de comunicação estreitaram pessoas e territórios se tornaram menos "distantes", o tráfico de pessoas, também acompanhou este processo, tanto se refinando quanto às técnicas de aliciamento, quanto aos mecanismos de ocultação de suas ações.

O TIP não é questão recente, contudo, vem alcançando pautas jornalísticas globalmente quanto à sua periculosidade de criminosos e da morosidade nas esferas do judiciário ${ }^{2}$, ao vertiginoso aumento do número de casos ${ }^{3}$ que acaba por colocar países na esfera de atenção $0^{4}$, assim como quanto às suas redes de organizações criminosas ${ }^{5}$ que, inclusive, podem contar com autoridades do mundo da política e dos negócios ${ }^{6}$. Neste sentido, o TIP se apresenta como um crime de caráter transnacional, o qual, no entender de Freire (2017), Nucci (2015), Rodrigues (2013) e Smith (2017), demanda cooperação internacional, por enfrentar diferentes jurisdições externas.

Concomitantemente, o TIP concebe questões em duas frentes: 1) o debate teórico que envolve prostituição, exploração sexual e a neutralidade de gênero nas abordagens do problema; 2) o desenvolvimento normativo de proposições teóricas e práticas acerca da conciliação entre normas gerais no âmbito do Direito Internacional e sua aplicação, posterior, pelas nações em ambiente doméstico. Os dois confrontos teóricos têm como norte os conflitos acerca das dimensões entre autonomia versus submissão (no aspecto do corpo e seu caráter de "propriedade") e soberania estatal versus cooperação internacional (na legislação de combate a este tipo de crime). Neste sentido, importa uma concepção enraizada em fenômenos e conjunturas políticas que não devem ser dissociadas em leituras apenas jurídicas ou apenas sociais (Baptista, 2020b).

Até 2013, de um a quatro milhões de pessoas foram traficadas todos os anos em vários lugares no mundo. Apenas na América Latina, em 2005 seriam contabilizadas 250mil pessoas em condições análogas à escravidão, em que 43\% dessas vítimas foram usadas na exploração sexual comercial e 32\% na exploração econômica. Indícios apontam que o TP como a terceira fonte ilegal de lucro no mundo, antecipado pelo tráfico de armamentos e o de drogas, rendendo 12 bilhões de dólares ao ano até 2013, podendo chegar a 31,6 bilhões em outras estimativas de outros órgãos (Secretaria Nacional de Justiça, 2013).

Outro Relatório Global de Tráfico de Pessoas de 2018, este sobre a América do Sul, aponta que o Brasil registrou 177 casos de TP registados entre 2014 e 2016. Já o número de vítimas de TP detectadas entre 2015 a junho/2017 era de 1159 adultos e 69 crianças em 2015, 750 adultos e 304 crianças em 2016 e 131 adultos e 2 crianças entre jan/jun de 2017. No âmbito da exploração sexual, referente às mulheres e meninas: 26 e 18 em 2014, 51 e 50 em 2015 e 33 e 42 em 2016 (Unodc, 2018).

O Relatório Nacional sobre o Tráfico de Pessoas elaborado pelo Ministério da Justiça em colaboração com o United Nations Office on Drugs and Crime (UNODC), destaca a invisibilidade das estatísticas dos crimes, pois "quase nenhuma das polícias levanta as características das vítimas quando do registro das ocorrências, nem sequer o gênero", sendo necessário recorrer às instituições que prestam assistência social afim de delimitar o perfil da vítima e às instituições jurídicas criminais para acesso ao perfil do traficante. Os dados do relatório confirmam as pessoas do sexo feminino como vítimas preferenciais do

\footnotetext{
${ }^{1}$ A partir deste ponto utilizaremos Tráfico Internacional de Pessoas (TIP) e Tráfico de Pessoas (TP) como sinônimos para o mesmo fato, sendo que o primeiro tem caráter internacional e envolve migração e o segundo é interno ao território doméstico de um país. Quando pertinente, delimitaremos territorialmente.

${ }^{2}$ Recuperado de https://www.unoentrerios.com.ar/policiales/una-decada-juicios-y-27-condenas-explotacion-sexual-rios-n2595134.html

${ }^{3}$ Recuperado de https://www.theguardian.com/world/2020/jan/07/thailand-hit-by-record-number-of-human-trafficking-cases

${ }^{4}$ Recuperado de https://www.scmp.com/news/hong-kong/law-and-crime/article/3090717/us-and-hong-kong-embroiled-human-trafficking-row-after

${ }^{5}$ Recuperado de https://g1.globo.com/ba/bahia/noticia/2020/06/10/operacao-da-pf-para-desarticular-organizacao-de-trafico-internacional-de-droga-e-realizadana-bahia-e-goias.ghtml
}

${ }^{6}$ Recuperado de https://www.nytimes.com/2020/07/05/us/politics/prince-andrew-jeffrey-epstein.html 
tráfico para fins de exploração sexual e relativo equilíbrio no tráfico para fins de trabalho escravo. Quanto à idade, a faixa etária entre 10 e 29 anos consiste em cerca de 50\% (Ministério da Justiça;2017).

O relatório também salienta a dimensão da vulnerabilidade social como fator que impacta no alcance dos traficantes na manipulação das vítimas. Birol e Barbosa (2014) apontam a vulnerabilidade como o contexto momentâneo, criado ou préexistente, que fragilize a tomada de decisão que coloque a pessoa em situações de risco ou de exploração. De acordo com relatório das Nações Unidas, a vulnerabilidade pode ser relativa às características individuais de determinada pessoa (vulnerabilidade pessoal), ao contexto em que as pessoas passam (vulnerabilidade situacional) ou à contexto particular social (vulnerabilidade circunstancial), como desemprego e pobreza (United Nations Office on Drugs and Crime, 2012).

Van Dijck (2005) considera estes contextos de vulnerabilidade os push factors, que empurram essas pessoas para o tráfico, especialmente grupos que tenham alguma relação de marginalidade, hierarquização de lacunas de autonomia enquanto grupo político (crianças, adolescentes, mulheres, homossexuais, pessoas com deficiência, dentre outros). Neste contexto, se configura o TIP: um crime transnacional organizado em redes que envolvem diversas jurisdições legais, cujas vítimas se caracterizam pela vulnerabilidade (que aumenta o potencial de engodo dos traficantes) e exploração.

Assim, o que se percebe é a necessidade de articulação de diversos elementos sociais, políticos e econômicos que possam dar conta de um fenômeno multifacetado, que possui implicações econômicas (pela miserabilidade, condições estruturais e pobreza), sociológicas (busca por oportunidades e fuga de mecanismos de subordinação) e políticas (conflitos e guerras) que impactam nos contextos migratórios, os quais, podem ou não impactar, igualmente, nas formas como o TIP se institucionaliza. Ao mesmo tempo, questões jurídico-civis de uma base que fragiliza ou empodera o status jurídico-civil das vítimas é um aspecto que pode impactar no desmantelamento ou não do TIP. Não obstante, os contextos que o TIP está permeado à estrutura políticoeconômica de uma nação também é um fator crítico.

Neste sentido, o objetivo deste trabalho é delimitar um esquema analítico sobre o TIP, considerando suas peculiaridades, em busca de uma concepção sociológica que avalie, ao menos sua delimitação conceitual, a noção da pessoa traficada e o status da vítima. Metodologicamente, trata-se de estudo de caráter exploratório, afim de alcançar objetivo descritivo, a partir de procedimentos bibliográficos, documentais e estatísticos.

Dividimos o presente ensaio em três partes. Na primeira delimitamos o conceito de tráfico, conjugando suas dimensões imprecisas, controvérsias e consensos teóricos. Na segunda parte, apontamos a necessidade de uma concepção sociológicajurídica do TIP e levantamos as conjugações sociais que implicam o reforço dessa concepção. Em seguida, concebemos as disputas no âmbito da pessoa traficada e tecemos análise acerca da perspectiva ideal de garantia do direito do status da vítima. Ao fim, trazemos as considerações finais. Remetemos à ideia de que uma concepção política do Tráfico Internacional de Pessoas demanda uma concepção sociológica que analise as dinâmicas sociais, tendo em vista a garantia de direitos à vítima, afim de que se rompa o este crime.

Procuramos, com este ensaio, descrever três esquemas (conceitual, sociológico-jurídico e político) que podem permitir, em conjunto, uma leitura mais precisa de um crime não pode mais ser lido sob apenas uma lente. Com o esquema conceitual, há de se delimitar o tráfico afim de tornar sua conceituação mais precisa e menos confusa quanto aos crimes correlatos. Com o esquema sociológico-jurídico, deve-se considerar como o tráfico não apenas parte, mas se conjuga com as dinâmicas sociais da localidade, das pessoas, das instituições políticas e legais. Com o esquema político, é fundamental considerar como a vítima é percebida em seu status civil, político e jurídico. Não obstante, os três esquemas podem permitir, em conjunto, uma leitura mais precisa de um crime não pode mais ser lido sob apenas uma lente. 


\section{Metodologia}

O objetivo deste trabalho é delimitar um esquema analítico sobre o TIP, considerando suas peculiaridades, em busca de uma concepção sociológica que avalie, ao menos sua delimitação conceitual, a noção da pessoa traficada e o status da vítima. Assim, metodologicamente, esta pesquisa se classifica como de finalidade básica, de abordagem qualitativa, com objetivo exploratório, pautando-se pelo apoio de procedimentos bibliográficos, documentais e aporte estatístico (Pereira et al, 2018).

Partimos da noção de tráfico em sua origem histórica (Cabezas, 2016; Venson, 2013; Weekes, 2006), que congrega mobilidade e acesso relativo à fronteiras e crimes que envolvem o interesse do Estado (Choi, 2014; Meshkovska Et Al 2015; Munro, 2006; Venson \& Pedro, 2013), incluindo as noções disputadas governamentalmente (Parliament of The United Kingdom, 1885; United Nations, 1904, 1921, 1933). Delimitamos, também, o uso político do TIP para o controle de corpos e moralidade em termos civil e juridicamente na composição da sociedade (Choi, 2014; Zuquete; Souza \& Deslandes, 2016).

Em termos de objeto, o TIP consideramos o exagerado foco na justiça criminal essencialmente mais reativo do que preventiva, cujo foco é a coerção, e prisão em contexto de transnacional (Anwary, 2007; Ausserer, 2008; Cho, 2013; Choi, 2014; Lansink, 2006; Munro, 2006; Shelley, 2003; Singh, 2004) com pouca abordagem específica quanto às condições de desigualdades sociais que levam as pessoas serem vitimadas pelo tráfico (Cho, 2013; Singh, 2004; Watson \& Silkstone, 2006).

Por fim, delimitamos o debate formado acerca de se refazer os processos jurídico-civis do TIP afim de costurar o reconhecimento do status de vítima das pessoas que sejam vitimadas pelo tráfico (Cabezas, 2016; Frescura, 2016; Munro, 2006; Santos; Gomes; Duarte, 2010; Weekes, 2006; Zuquete; Souza \& Deslandes, 2016). Por outro lado, destacamos que o TIP é consensuado em termos de prática que configura uma violação de Direitos Humanos por atingir a integridade da vítima em suas várias dimensões. (Choi, 2014; Frescura, 2016; Lansink, 2006).

\section{Resultados e Discussão}

\subsection{Delimitando o tráfico de pessoas: um esquema conceitual}

De acordo com Anamaria Venson e Joana Pedro (2013), o tráfico de pessoas é um conceito jurídico originado no século XIX, sendo resgatado no século XX, nascido associado à discursividade de policiamento das fronteiras transnacionais, o que dissocia dimensão humanitária exclusiva em lógica de direitos humanos. As preocupações iniciais se direcionam à rejeição do tráfico de pessoas negras e posteriormente, as mulheres brancas para fins de prostituição. No caso de mulheres brancas, o racismo e o ideal de pureza feminina se desenvolveram conjuntamente à prostituição como desvio social e obstáculo à civilização e à moralidade. Esta era o elemento persecutório a limpar a sociedade desta doença que corromperia a família, o casamento, o trabalho e a propriedade.

Como características próprias desse período inglês, a composição do uso político do TIP para o controle de corpos e moralidade se fazia presente civil e juridicamente na composição da sociedade (Choi, 2014; Zuquete; Souza \& Deslandes, 2016). Este controle conjugava a pureza feminina como parte intrínseca de uma fundamentação moralista à mulher, sobretudo, abrangendo a prostituição, (Abu \& Zarhin, 2019; Cabezas, 2016; Desyllas, 2007; Venson \& Pedro, 2013; Weekes, 2006). Ao mesmo tempo em que situava uma linha entre as mulheres puras e as "sujas", onde as primeiras devem ser protegidas pela sua dignidade à sociedade (Abu \& Zarhin, 2019; Ausserer, 2008; Cabezas, 2016; Santos; Gomes \& Duarte, 2010; Singh, 2004).

Para Anna Weekes (2016), o início das legislações anti-tráfico remonta ao período Vitoriano do século XIX ${ }^{7}$, marcado pela proteção das escravas sexuais brancas, na qual se inferioriza a capacidade autônoma das mulheres procurarem melhores

\footnotetext{
${ }^{7}$ Ver o Criminal Law Amendment Act de 1885 do Parlamento do Reino Unido, que trata da proteção de mulheres e meninas, criminalizando estupro de mulheres e indicando a idade mínima de 13 anos para qualquer relação sexual. Mulheres que sejam prostitutas ou que possuam caráter "imoral” estão fora dessa "proteção". Ver mais em Parliament of the United Kingdom (1885).
} 
condições de vida e se buscava afirmar controle físico, territorial e de sexualidade sob alcance de pretensa proteção à potencial vitimização via tráfico sexual. Apesar de datarem como problemática, a autora aponta que seus resquícios estão presentes na legislação em vários países, a exemplo da sul-africana.

É desse período entre o fim do século XIX e início do Século XX que surgem as convenções internacionais específicas sobre TIP com foco nas mulheres, sendo a mais conhecida, o Acordo Internacional para Supressão do Tráfico de Mulheres Brancas, de 1904, chamado "Protocolo de Paris", que observava uma abordagem específica de controle de movimentação de mulheres brancas e sua "proteção" (United Nations, 1904). Este protocolo foi alvo de inúmeros debates por ter um cunho racista (já que seria vergonhoso traficar mulheres brancas apenas), além de ter sido assinado em contexto de ampliação em postos de trabalho nas indústrias por mulheres, assim como predizia reação ao aumento da prostituição (Choi, 2014; Munro, 2006; Swanson, 2016)

Venson e Pedro (2013) ressaltam a invenção da dissociação entre a mulher e a doença, igualmente colocando a prostituição no contexto da medicalização e policiamento da sexualidade no início das primeiras formulações sobre o tráfico no século XIX. Apenas no século XX, em 1949, tráfico denota dimensão coordenada internacionalmente com a adoção pela Assembleia Geral das Nações Unidas, mediante a Convenção para Eliminação do Tráfico de Pessoas e Exploração da Prostituição de Outros. A Convenção associava exploração sexual, pelo tráfico, em atentado à dignidade humana e aos direitos fundamentais.

Há também a Convenção Internacional para a Supressão do Tráfico de Mulheres e Crianças, de 1921, que equiparava mulheres e crianças a vítimas a serem tuteladas, sem nenhuma referência a questões raciais, todavia, é a convenção que inicia a equiparação entre crianças e mulheres como vítimas iguais (United Nations, 1921). Esta convenção tem uma segunda rodada de negociações em 1933 com a Convenção para a Repressão do Tráfico de Mulheres Maiores, que criminalizou qualquer recrutamento que decorra em prostituição, independente do consentimento da vítima (United Nations, 1933). Este tratado tem relações próximas com a Convenção para a Supressão do Tráfico de Pessoas e da Exploração da Prostituição de Outros, de 1949, que reprimia efusivamente o ato da prostituição, vinculando-o ao tráfico e iniciando uma confusão entre crimes, adotando posição criminal com pouca atenção às vítimas. Este é o denominado "viés abolicionista" na prostituição que permanece nas Nações Unidas até o século XXI (Cockbain \& Bowers, 2019; Choi, 2014; Meshkovska, 2015).

Por fim, a normativa internacional mais recente se refere ao Protocolo Adicional à Convenção das Nações Unidas contra o Crime Organizado Transnacional Relativo à Prevenção, Repressão e Punição do Tráfico de Pessoas, em especial de Mulheres e Crianças (Chamado de Protocolo de Palermo, de 2000, delimitando a expressão Tráfico de Pessoas como:

$\mathrm{O}$ recrutamento, o transporte, a transferência, o alojamento ou o acolhimento de pessoas, recorrendo à ameaça ou uso da força ou a outras formas de coação, ao rapto, à fraude, ao engano, ao abuso de autoridade ou à situação de vulnerabilidade ou à entrega ou aceitação de pagamentos ou benefícios para obter o consentimento de uma pessoa que tenha autoridade sobre outra para fins de exploração. Exploração inclui, no mínimo, a exploração da prostituição ou outras formas de exploração sexual, trabalho ou serviços forçados, escravidão ou práticas similares à escravidão, servidão ou a remoção de órgãos (United Nations Office on Drugs and Crime, 2004, p. 42).

A Convenção de Palermo, é o principal instrumento global de combate ao crime organizado transnacional. Ela foi aprovada pela Assembleia-Geral da ONU em 15 de novembro de 2000, data em que foi colocada à disposição dos Estadosmembros para assinatura, e entrou em vigor no dia 29 de setembro de 2003. A Convenção é complementada por três protocolos que abordam áreas específicas do crime organizado: o Protocolo Relativo à Prevenção, Repressão e Punição do Tráfico de Pessoas, em Especial Mulheres e Crianças; o Protocolo Relativo ao Combate ao Tráfico de Migrantes por Via Terrestre, Marítima e Aérea; e o Protocolo contra a fabricação e o tráfico ilícito de armas de fogo, suas peças e componentes e munições. 
Jo Goodey (2004, p. 27) pondera o tráfico sexual como "fenômeno generificado envolvendo, primariamente, a exploração sexual forçada, por homens, de mulheres economicamente marginalizadas”. O tráfico de pessoas é um fato associado, ao menos em sua intensificação no século XX, aos aspectos da globalização, que incitou mobilizações territoriais por uma série de fatores. Para a autora, a fragilização de vínculos trabalhistas e de seguridade social, compõem um dos elementos formadores de pressões que restringem a escolha das mulheres e podem ser suscetíveis às tentativas de propostas de trabalho que, podem ou não estar explícitas a sua propensão à atividade sexual, mas que tornam propostas "irrecusáveis" à uma pessoa fragilizada. Baptista (2020a, 2019) também pondera a respeito de que esta generificação da violência tem relações com as condições sociais, políticas, institucionais e econômicas das mulheres, vulnerabilizando seus contextos e expondo-as à violência em maior intensidade.

Este contexto internacional de fronteiras, moralidade e uso político do TIP se reconfigura a partir de fenômenos da globalização ao longo do fim do século XX e início do XXI, em que a porosidade das fronteiras geográficas se mostram mais evidentes, ampliando o acesso de indivíduos e circulação de pessoas, diversificando a composição deste fenômeno para um caráter globalizado de tráfico e não mais relacionado à localidades, a exemplo de países europeus apenas (Ne, 2018; Petersen, 2001; Watson \& Silkstone, 2006). Ao mesmo tempo, a ampliação de mercados, circulação de pessoas, bens e serviços, além da financeirização dos negócios, bem como o aumento da pobreza e miséria em países fragilizados social e politicamente, acabam por estimular migrações em busca de oportunidades, criando contextos facilitadores para traficantes (Anwary, 2007; Lansink, 2006; Ling, 2018; Petersen, 2001; Swanson, 2016).

O tráfico de pessoas possui longo histórico de ser fenômeno de intensa intervenção estatal, seja em aspectos criminológicos, de defesa nacional, moralidade, pureza feminina ou aversão à miscigenação. A diferença para o contexto do século XXI é que, para Munro (2006) a globalização dificulta ter uma delimitação direta entre vítima, agente do tráfico, redes, cliente e o Estado. As desigualdades socioeconômicas, instabilidades políticas, buscas individuais por melhores oportunidades de vida, por exemplo, confundem a capacidade analítica de delimitação coordenada de ações por governos em seu próprio território doméstico, não obstante suas relações internacionais sobre a matéria.

Conceitualmente, o TIP detém uma dificuldade de delimitação quanto ao tipo, agente e vítima, especificamente por não envolver apenas um único tipo penal, quando inscrito juridicamente, ou um tipo de relações entre vítima ou agente, quando situado sociologicamente, ao mesmo tempo em que o TIP é associado à uma série de conjunturas socioeconômicas e políticoinstitucionais que dificultam uma delimitação precisa (Goodey, 2004; Lansink, 2006; Stoyanova, 2017; Weekes, 2006). Assim, concepções sociológicas ou jurídicas se entremeiam nas concepções de TIP que as nações adotam.

As principais dificuldades em delimitar o tráfico de pessoas estão, primeiro, em sua natureza ilegal obscura, além da falta de dados e registros governamentais, o que dificulta situar o problema e pensar em soluções. Paralelamente, a confusão entre tráfico e contrabando, aliado ao medo das vítimas, cria contexto de redução de políticas efetivas (Goodey, 2004). Outra questão recai na dimensão da tutela, proteção e redução da agência das vítimas, que dificulta ter aproximação com as mesmas.

Por outro lado, o TIP é consensuado em termos de prática que configura uma violação de Direitos Humanos por atingir a integridade da vítima em suas várias dimensões. (Choi, 2014; Frescura, 2006; Lansink, 2006). Notadamente, é um tipo de crime em que as mulheres são as principais vítimas, delimitando o TIP como um fenômeno generificado de exploração da mulher (Anwary, 2007; Desyllas, 2007; Goodey, 2004; Munro, 2006; Petersen, 2001; Santos; Gomes \& Duarte, 2010; Watson \& Silkstone, 2006; Weekes, 2006). Há, ainda, um relativo entendimento de que o TIP determina um processo de commoditização da mulher, por conta de uma precificação do corpo em atividades de exploração sexual e trabalho (Choi, 2014; Goodey, 2004; Meshkovska Et Al, 2015; Watson \& Silkstone, 2006).

José Zuquete, Edinilsa Souza e Suely Deslandes (2016) consideram que as imprecisões conceituais, legais e burocráticas (de apoio), associadas às vinculações morais e ideológicas, tornam o tráfico de pessoas, em especial, o tráfico de mulheres, um 
processo de difícil conciliação entre posições que orbitam entre direitos e violência de gênero. Ainda assim, os autores entendem que o uso político do conceito e/ou prática do tráfico se desenvolve em contextos aliados à proteção em alguma perspectiva e, do outro lado, de criminalização.

Em termos de alcance, o TIP possui uma associação ao contexto global para com sua dimensão criminológica, tendo em vista ser um crime realizado em redes e grupos de organizações criminosas espalhadas em matrizes mundo afora (Choi, 2014; Ne, 2018; Shelley, 2003; Watson \& Silkstone, 2006; Zuquete; Souza \& Deslandes, 2016). Estas redes aproveitariam elementos típicos da globalização, a exemplo da pobreza e miséria, como um fenômeno de destituição generalizada que colocarias as pessoas, em especial as mulheres, em relação de pauperização e desespero, para que aceitem "oportunidades" de trabalho no exterior, ao passo em que igualmente aproveitam as brechas legais para estes processos (Ausserer, 2008; Cabezas, 2016; Choi, 2014; Ghosh, 2014).

Munro (2006) aproveita estes contextos para construir argumentação de que é preciso considerar outras formas de exploração no tráfico de mulheres, que não se atente apenas à questão sexual, incorporando, portanto, outras formas não-sexuais, que podem ter artifícios mais sutis ao aliciamento, aprisionamento e exploração, que pouco demonstram visibilidade às ações da organização criminosa. Até mesmo para que se compreenda que a exploração não é apenas a sexual, não se limitando e nem se confundindo com.

Para Weekes (2016, p. 32), "há uma confluência entre o tráfico de pessoas e o trabalho sexual", como um problema de gênero, notadamente, por as mulheres serem consideradas anormais ou desviantes quando trabalham com sexo, ou seja, a dimensão da pureza e honra retornam ao contexto moralizador que circunda as mulheres. Assim, uma mulher não migraria a outro país para trabalhar com sexo, a menos que seja de modo forçado. Daqui surgem duas posições: 1) os que demonstram não existir dados que confirmem que toda prostituição é forçada; 2) e os que entendem que a prostituição leva ao tráfico de pessoas. É, nesta conjuntura complexa em que se procura diferenciar migração ilegal, tráfico de pessoas para fins de exploração sexual e o tráfico de pessoas.

Neste aspecto, essa confusão é um resquício moralista do período Vitoriano, o qual ainda permanece no século XXI, notadamente quando da proibição da prostituição, mas não da sua criminalização, ou seja, o ato de prostituir-se ou facilitar a prostituição, em muitas nações, é considerado um crime, mas a pessoa que se prostitui não é agente ativo de um crime, pelo contrário, é vítima da conjuntura do crime (Venson \& Pedro, 2013; Weekes, 2006). Não é à toa que muitas críticas feministas asseveram que este posicionamento é delimitador de um perfil de vítima (feminina) em situação de passividade, que demanda tutela por sua total agência reduzida (Abu \& Zarhin, 2019; Choi, 2014; Goodey, 2004; Lansink, 2006; Weekes, 2006). Inclusive, a relação de moralidade, prostituição e TIP importa em dificuldades de se analisar contextos quando da prostituição voluntária.

Uma das interpretações dominantes sobre o tráfico de pessoas, fragilmente formulada, é que este crime seria derivado da migração forçada, ou seja, um imigrante ilegal seria potencial vítima do tráfico em algum momento (Ausserer, 2008). Esta interpretação tem respaldo no artigo 3, item "a" da Convenção de Palermo que relaciona o tráfico ao abuso da força e coerção, assim como violência e manipulação como aspectos do tráfico. O problema em si é a desconsideração da possibilidade da ocorrência do tráfico mesmo com uma migração legalizada. Por exemplo, uma pessoa contrata um intermediário para agilizar vistos e demais documentos necessários à entrada legal em um país, quando da entrada é ameaçado com valores não previsto, tem seus documentos retidos e fica à mercê do tráfico.

Vladislava Stoyanova (2017) avalia sobre definições normativas (a exemplo da Convenção de Palermo) que sugerem não ter relação entre tráfico de pessoas e escravidão, servidão ou trabalho forçado, já que o tráfico pode ou não resultar na exploração, ou seja, se refere ao processo e não ao conceito. Neste aspecto, a autora considera o conceito normativo como ineficaz, por ser pouco explicado. Isso faz com que a definição de "exploração" de Palermo, como propósito do tráfico de pessoas, precisa estar associada com certas ações e certos meios para que se constitua como tal. 
Um elemento legalístico importante deste processo, é que os mecanismos de combate internacional situariam apenas um limite jurídico e não sociológico deste fenômeno, desconsiderando motivos e contextos de sua criação, manutenção e ampliação como um elemento parte da cadeia de "negócios" que existem em vários países (Ausserer, 2008; Desyllas, 2007; Shelley, 2003; Stoyanova, 2017). Por este sentido, é comum que se confunda, jurídica e até sociologicamente, a prostituição com o TIP, os quais, em certa medida, podem ter relações, mas não devem ser confundidos, pois, a sua confusão, pode impedir ações efetivas de combate às concepções de fenômenos distintos, porém próximos (Cockbain \& Bowers, 2019; Farrell \& Pfeffer, 2014; Weekes, 2006).

Meshkovska et al (2015) delimitam que, o processo em si do tráfico sexual de mulheres, abrange quatro fases: 1) o recrutamento (das vítimas, especialmente via vulnerabilidades); 2) a experiência do tráfico (a que a vítima é submetida, assim como o modus operandi do crime organizado); 3) a identificação (pelos traficantes acerca das potenciais vítimas do tráfico); 4) a recuperação e reintegração (das vítimas, onde o status da vítima é recuperado com abordagem centrada nos direitos e não na censura). Apesar de os autores indicarem que estes são elementos comuns, isso não significa que sejam obrigatórios, tendo em vista que as experiências se transformam de acordo com uma série de fatores que podem situar outras relações de atores em contextos distintos. Este é um processo ideal, distante da reatividade presente no TIP.

Em termos de objeto, o TIP envolve um foco na justiça criminal muito mais reativa do que preventiva, cujo foco é a coerção, e prisão em contexto de transnacional (Anwary, 2007; Ausserer, 2008; Cho, 2012; Choi, 2014; Lansink, 2006; Munro, 2006; Shelley, 2003; Singh, 2004) com pouca abordagem específica quanto às condições de desigualdades sociais que levam as pessoas serem vitimadas pelo tráfico (Cho, 2012; Singh, 2004; Watson \& Silkstone, 2006). Uma das indicações desta pouca abordagem recai nas dificuldades que envolvem as práticas culturais como desafio às ações internacionais coordenadas por múltiplas nações, uma vez que, determinadas práticas culturais associadas ao TIP não seriam tipificadas como crimes, tornando a abordagem internacional mais complexa pela relação local/global (Ghosh, 2014; Meshkovska, et al, 2015; Singh, 2004; Weekes, 2006; Zuquete; Souza \& Deslandes, 2016).

Vemos isso na diferenciação entre migração forçada e migração legal, onde, em ambas podem ocorrer o tráfico, e é importante dissociar, por delimitar formas conceituais que se relacionam à diferentes mecanismos de aliciamento, coerção, exploração, assim como o desenvolvimento das redes de tráfico mais atentas às mudanças nas leis. Não obstante, as duas formas se situam distintamente no plano internacional em termos de direito. Em paralelo, ressalta Ausserer (2008: 100), que nesta confusão entre migrações, o imigrante ilegal é o Outro, um "estrangeiro indesejável", criador de problemas e que precisam ser controlados, especialmente, mentes e corpos para notarem a intolerância do espaço. Neste ponto, a autora entende que as políticas anti-tráfico assumem este papel.

Biljana Meshkovska et al (2015) definem o tráfico a partir de três elementos: 1) ação; 2) meios; 3) objetivos. Apenas o objetivo de exploração se mantém estável, em que a ação e os meios podem variar conforme tipos distintos de tráfico, as formas como os criminosos se organizam, o alcance das leis, dentre outros fatores. O tráfico não é um processo apenas, pois inclui a manutenção das condições de exploração das pessoas. Estres três elementos podem se articular conforme tecnologia empregada no ato do tráfico, os meios financeiros envolvidos na transação, assim como a necessidade ou não da coerção para com a vítima. O objetivo da exploração, assim, permanece estável no sistema. E ela é o foco das controvérsias.

Os debates principais no âmbito do tráfico de mulheres para fins de exploração congregam sua definição em si e o consentimento. Quanto à definição, ainda persistem concepções racistas e moralizantes que diferenciam mulheres brancas de não-brancas, assim como a controvérsia da prostituição (Meshkovska et al 2015). Em relação ao consentimento, existem dificuldades em dois momentos: primeiro, para com o sentido de consentir sob contextos que reduzem a capacidade de escolha livre e, em segundo, quando da linha entre uma migração legal "termine" com o início de um processo de tráfico e exploração não consentida. 
A questão da Justiça apresenta contornos ainda mais complexos no TIP, quando se considera este como provido de uma Justiça de Gênero hierarquizada que possui centralização masculina dos mecanismos de combate a este crime, ou seja, mecanismos que focam em uma pretensa agência reduzida das vítimas e processo de tutela que as considera como incapazes de reagirem (Anwary, 2007; Choi, 2014; Goodey, 2004; Petersen, 2001; Swanson, 2016). Neste ponto, um debate vem se formando acerca de se refazer os processos jurídico-civis do TIP afim de costurar o reconhecimento do status de vítima das pessoas que sejam vitimadas pelo tráfico (Cabezas, 2016; Frescura, 2006; Munro, 2006; Santos; Gomes \& Duarte, 2010; Weekes, 2006; Zuquete; Souza \& Deslandes, 2016).

Outra corrente deste debate propõe uma abordagem centrada na mulher, cuja concepção procura enfatizar a generificação deste crime, destacando as mulheres como vítimas mais atingidas, logo, um tipo de crime que requer abordagens específicas para com este "perfil" (Farrell \& Pfeffer, 2014; Goodey, 2004; Singh, 2004; Watson \& Silkstone, 2006), cujo objetivo maior é a proteção e cuidado afim de ampliar o status e não reduzir a vítima (Cabezas, 2016). Neste sentido, tem-se a ideia do TIP a partir de um processo de prevenção, proteção e persecução no contexto de criar mecanismos mais eficazes que se afastem de concepções de pureza e moralidade, assim como a confusão com a prostituição, entendendo o fenômeno do TIP como multifacetado e que demanda ações ampliadas às vítimas (Anwary, 2007; Farrell, 2014; Goodey, 2004; Meshkovska, 2015; Munro, 2006; Singh, 2004; Swanson, 2016; Venson \& Pedro, 2013; Weekes, 2006).

Quanto à abordagem, o tráfico sexual de mulheres circula pelas dimensões da Segurança Pública, Migrações e Direitos Humanos (Meshkovska et al 2015). A questão da Segurança remete à discussão realizada por Ausserer (2008) de tomar o tráfico e migrações ilegais como crimes equiparados de ameaça à ordem social e, por isso, seus agentes devem ser eliminados. Quanto à migração, a recorrente confusão com tráfico e prostituição. Por fim, a ótica dos Direitos Humanos, que se discute os impactos do tráfico em destituir generalizadamente as pessoas, como indica Ghosh (2014).

Contudo, ressalte-se que o TIP, como um fenômeno global, atuante em células e ramificado em organizações criminosas que se aproveitam de brechas legais para desenvolver estes "negócios", estruturam o TIP como incapaz de ser enquadrado territorialmente, o que demanda reconfiguração dos mecanismos convencionais de prevenção, proteção e persecução. Para tanto, o TIP deve abordar um contexto que conjugue pactos e convenções do Direito Internacional, como forças de lei, para com as bases jurídicas domésticas dos territórios de origem ou destino do TIP para instauração de sistema de cooperação internacional (Lansink, 2006; Singh, 2004; Swanson, 2016; Watson, 2006; Zuquete; Souza \& Deslandes, 2016). Por fim, este processo precisa ser parte de uma Agenda Política internacional com caráter doméstico, que agregue as duas dimensões como conciliáveis e não concorrenciais por disputas que envolvem fronteiras, mercados e processos (Lansink, 2006; Meshkovska, 2015; Munro, 2006; Petersen, 2001; Swanson, 2016).

\subsection{Por uma concepção sociológica-jurídica do tráfico: um esquema ampliado das dinâmicas e contextos sociais}

Annette Lansink (2006) considera que a maioria das mulheres traficadas são migrantes que deliberam conscientemente à migração, enquanto que uma parte é vendida ou sequestrada. Este é um ponto importante, que demarca uma característica do tráfico para fins de exploração sexual: a ludibriação inicial à migração e a chantagem posterior à chegada em território estrangeiro. As motivações à migração são inúmeras, especificamente de caráter econômico e de busca de melhores condições de vida e oportunidades, que não eram suficientes em território de origem. Estas expectativas são manipuladas por traficantes afim de trato sentimental ao convencimento em relação às potenciais vítimas.

Os imigrantes passam a assumir contorno negativo que se estrutura em dimensões xenófobas, racistas e moralizantes, servindo de espelho à população local. No caso das mulheres, isso se mescla com a pureza das residentes nacionais, o combate à prostituição trazida pelas "estrangeiras", ou seja, constroem-se dinâmicas nacional-internacional que incidem em forte controle territorial doméstico. Este, que é seguro, ao contrário do outro. Ressalta Ausserer (2008) que é preciso concepção sociológica e 
não apenas jurídica, que observe como direitos são negados e concedidos na manipulação destes processos que envolvem migrações e tráfico. A cidadania torna-se assim, elemento de diferenciação de pessoas atingidas por estes aspectos. Por fim, a autora ainda comenta sobre a ideia de "eliminação do outro", onde estas políticas são levadas aos extremos - tal eliminação pode ser física, moral, social ou legal.

Seo-Young Cho (2012) analisa que é preciso correlacionar impactos da globalização em diferentes esferas, quando da observância do impulso no tráfico de pessoas. A autora aponta que, do ponto de vista social, a globalização pode ter incrementado as lutas de mulheres e influenciado na obtenção de direitos. Por outro lado, a globalização econômica não necessariamente teve o mesmo impacto geral, o qual, inclusive, foi diferenciado entre as mulheres, marginalizando as estrangeiras. Cho ainda argumenta que a globalização econômica intensificaria o tráfico, enquanto que a globalização social a reduziria.

A globalização impacta em fluxos informacionais e contatos pessoais, que pouco colidiriam economicamente com as vidas das mulheres, ainda permanecendo altos índices de insegurança financeira que reduziria oportunidades de mulheres, especialmente as periféricas. Por outo lado, Cho (2012) entende que as discussões globais, a entrada de questões na agenda política, a atuação da mídia e de movimentos sociais, produziram alto impacto em termos de globalização social, construindo uma agenda de direitos, do mesmo modo, evidenciando a disparidade de contextos sociais vividos por mulheres. Para a autora, o tráfico se insere em duas perspectivas: 1) no aumento, quando da piora das condições socioeconômicas das mulheres, pela base econômica da globalização; 2) na redução, quando processos de direitos e violações são evidenciados e postos em público, pela base social da globalização.

A partir de dados do Mecanismo de Referência Nacional do Reino Unido, Cockbain e Bowers (2019) analisam que as pessoas vítimas de tráfico são jovens, mulheres (a maioria em tráfico sexual e serviços domésticos), do Leste Europeu. O gênero é fator marcante, já que dos três tipos de finalidade do tráfico analisados (sexual, serviços domésticos e trabalho forçado), as mulheres são maioria em dois. Ao mesmo tempo, há multiplicidade de nacionalidades, o que denota transnacionalidade. Um aspecto importante do estudo é a correlação entre as vocações produtivas de alguns territórios e o tipo de tráfico ali empreendido, o que pode auxiliar na previsão de padronização de crimes e técnicas do tráfico. As autoras defendem, neste caso, que delimitação de dados pode criar ações e programas eficazes e enfrentar o terreno pantanoso da falta de dados sobre o tráfico.

A questão do tráfico para fins de exploração sexual remete às multiplicidades de causas sociais e que tem vinculação à escravidão (como processo historicamente permitido inicialmente e garantidor de direitos de propriedade ao "dono" da pessoa escravizada". Para Santos, Gomes e Duarte (2010, p. 169), mesmo que sob forma diferente, em contexto criminalizado, o tráfico "se mantém via desigualdades e injustiças da distribuição de renda promovido e encorajado pelo Sistema Mundial”. Em lugares onde se prevalecem pauperização, sistemas sociais de proteção enfraquecidos, super-exploração da força de trabalho em condições subumanas, se delineiam contextos que favorecem o aliciamento de pessoas, notadamente, mulheres.

Este contexto social encontra na vítima em potencial sua própria legitimação pela deslegitimação da vítima, em que estereótipos apontam marginalização, pobreza, miséria, pureza e moralidade como elementos centrais ao tráfico de mulheres. A desumanização e demonização construída que pode romper a sociedade, a cultura e história locais, assim como as estruturas das relações de poder, são elementos evocados para delimitar ações que respaldem controle, autodeterminação e combate a este tipo de crime. Como ressaltam Santos, Gomes e Duarte (2010), a construção dos "Outros" em pleno contexto globalizante erguem imagens de mulheres associadas à prostituição e tráfico, nem sempre como vítimas, mas como coautoras deste contexto capaz de romper a sociedade.

Karen Petersen (2001) indica que a questão da manipulação como estratégia do tráfico se orienta pelo desespero, ansiedade ou insatisfação da vítima em relação à alguma dimensão socioeconômica ou político-institucional que pode ou não estar associado com uma conjuntura estrutural. De fato, há de se sopesar as dimensões estruturais que constroem as desigualdades que reduzem oportunidades e afetam condições de vida das pessoas. Por outro lado, deve-se ter em emente as aspirações 
individuais dos sujeitos. A priori, as políticas de combate ao tráfico, apesar de se atentarem às perspectivas sociológicas do tráfico, ainda se mantém distantes. Este afastamento é evidenciado por Petersen (2001) quando destaca esta manipulação por falsas promessas relacionadas às conjunturas que afetam as pessoas

Os protocolos e as redes internacionais relativos ao tráfico e situação de mulheres já destacam a necessidade de cooperação internacional, seja econômico, legal, social, tecnológico ou produtivo, para que as condições sociais de países desfavorecidos melhorem de forma a reduzir potencial migração, pelo fato de contextos paupérrimos locais (Lansink, 2006). A ideia seria reduzir os elementos potencialmente articulados como fonte de barganha de organizações criminosas. Neste contexto, a dimensão do consentimento também variaria.

O tráfico não se confunde com outras formas de migração. O tráfico envolve: 1) elemento não-consensual; 2) seu objetivo é explorar o traficado, o que gera uma relação direta e manipulada pelo traficante; 3) sua territorialidade é transnacional. Uma peculiaridade que Lansink (2006, p. 48) ressalta é sua "ameaça com base no gênero", quando se observa que as mulheres são maioria das vítimas, cuja exploração é direcionada à prostituição, turismo sexual, trabalho doméstico, casamentos arranjados ou como objetos para estupro, por exemplo. Para a autora, as mulheres são as mais afetadas por desigualdades sociais, econômicas e políticas, tornando-as mais fragilizadas e potencialmente um alvo de traficantes, por seu desespero.

Desylla (2007) propõe um esquema que considere o contexto de dinâmicas sociais presentes nas migrações, evidenciando dimensões de exploração próprias, dos sistemas sociais que se relacionam com a exploração do tráfico. A autora sinaliza que as vítimas e grupos marginalizados devem falar por si, o que afasta as dimensões de resgate de uma vítima, cuja voz sequer é ouvida. Fundamental, ainda, é construir políticas de apoio às vítimas que não padeçam de estereótipos que revitimizem e construam imagem de coautor do crime, em vez de vítima.

Na questão do tráfico de mulheres, o elemento das desigualdades socioeconômicas é basilar ao entendimento dos motivos que inclinam mais mulheres do que homens a estarem em situação de vulnerabilidade. A pobreza e o analfabetismo, ainda, criam conjunturas que reduzem as oportunidades de envolvimento para mulheres. Quando traficantes encontram este desalento, uma porta se abre ao convencimento. Contudo, Divya Singh (2004, p. 342) aponta que existem casos de tráfico no Oeste da África, em que "traficantes deliberadamente estupram jovens mulheres para torná-las desvalorizadas pela perda de sua virgindade e, consequentemente, perder valor monetário como oferta de esposa". Assim, para a autora, além de uma rede, formase uma commodity em um grande mercado à disposição das quadrilhas.

Uma das maiores controvérsias está no entendimento sobre consentimento e abuso da vulnerabilidade. Pelo Protocolo de Palermo, consenso é relevante se coerção ou fraude forem evocadas como meios ao tráfico (Lansink, 2006). Mas e quanto às dinâmicas socioeconômicas paupérrimas que inclinam decisão de aceite à migração (em que, até este ponto, a vítima pode ou não saber que está sendo traficada)? Neste aspecto, se diferencia o momento em que o consentimento venha a ser quebrado, considerando que vítimas são manipuladas ou ludibriadas a pensar que se migrará para empregos livres de coerção.

Kiril Sharapov (2017, p. 92) entende que "o contexto e forma como o tráfico de pessoas é construído e problematizado cria um modo de conhecimento social, um discurso", que consequentemente, quando posto em prática "deriva em consequências reais para a vida de pessoas, cujas vozes podem não ter disso devidamente reconhecidas ou foram silenciadas". Amália Cabezas (2016), por exemplo, destaca que, a pesar de ser ilegal a oferta de serviços sexuais em bares de Porto Rico, mulheres que trabalham como garçonetes nestes ambientes e estejam sem documentos, precisam ser "gentis" e "atenciosas", tendo em vista que o consumo local é considerado atrativo. Ou seja, existem portas de entrada ao contexto do tráfico e exploração de mulheres não relacionadas às formas mais difundidas.

Cabezas (2016) ainda ressalta que as táticas de aliciamento de mulheres em condições ilegais (ou legais, mas sem situação socioeconômica desfavorável), se orientam pela vulnerabilidade e ingerência em que estas se encontram. Contextos que envolvem papeis e representações de gênero sexualizadas também são evocadas como mecanismo de aliciamento e intensificação 
das atividades do tráfico e exploração sexual. A autora ressalta como as construções de "hiperssexualidade" e "lascividade", igualmente, constroem a imagem de mulheres negras em Porto Rico, e que estão nesta situação, o que as coloca "fora das normas de gênero vinculadas à feminilidade 'respeitável'” (Cabezas, 2016, p. 11).

As narrativas raciais e racistas têm forte instrumentalização na criação das bases normativas no combate ao tráfico de mulheres desde as primeiras normas no século XIX, as quais, para Cabezas (2016, pp. 13-14) "foram capazes de dramatizar e articular uma agenda política feminista" que capitalizou a mobilização contra escravidão para reorientar a prostituição regulamentada (que focavam nas prostitutas e não nos clientes). Esta regulamentação acabou por "criminalizar e estigmatizar as mulheres jovens e as de classe trabalhadora que estavam se mudando para as cidades em busca de trabalho nas indústrias da nascente Revolução Industrial" (Cabezas, 2016, p. 14). Não obstante, a naturalização do desejo masculino como inato e incontrolável sustentou as mulheres prostitutas como vetores de doenças, mas os clientes ficavam fora do alcance destas leis.

Biswajit Ghosh (2014) situa, a partir de dados, que algumas regiões da Índia vêm tendo alterado o comportamento do tráfico de pessoas no século XXI, passando da finalidade sexual para setores comerciais e domésticos. Destaca que, com o endurecimento de leis e proliferação de ações policiais, o tráfico com fins de trabalho doméstico vem se apresentando como rota segura em vez do tráfico com fins sexuais. A princípio, isto pode parecer um retrato de efetividade das leis mais duras e programas de combate ao tráfico, entretanto, há de se considerar se não se trata de movimentação de atividades com finalidade de mais lucro com outras fontes e sem tanto risco.

A questão de o tipo do território ter influência no desenvolvimento de um tipo de tráfico visto em Cockbain e Bowers (2019), é observado em Ghosh (2014), onde as condições locais de pobreza e baixos rendimentos criam perspectivas desalentadoras às pessoas. As condições familiares, sua numerosidade ou o fato da existência de um único provedor, também criam condições que encontram a exploração destas pessoas. Assim, um processo de destituição generalizada é condição necessária à que traficantes e redes organizadas do crime tenham sucesso no aliciamento das vítimas. Fome, desnutrição, desemprego, pobreza, analfabetismo e exposição à insalubridade e doenças são mecanismos críticos manipulados pelos traficantes à uma "escolha" de caráter "deliberado" por condições mais favoráveis.

Para Ghosh (2014), sua pesquisa na Índia aponta especificidades nas causas que motivam tráfico de adultos e crianças. No caso de crianças e idosos, não há muita diferença entre as causas: todas circundam pobreza, desemprego e desconhecimento do fato do tráfico. No caso de homens adultos, o desemprego é a causa principal, já nas mulheres, a pobreza. Contudo, o autor sustenta que as vulnerabilidades que contextualizam mulheres são mais incisivas por conta de fenômenos históricos excludentes que rebaixam, ainda mais a já frágil situação das mesmas.

Moshoula Desyllas (2007, p. 58) defende uma definição de tráfico como "comércio e exploração do trabalho sob condições de coerção e força". A definição agrega, também, caráter transnacional migrantes e contextos de direitos humanos, que procura considerar desigualdades globais, colonialismo e imperialismo, além das experiências de mulheres em sua dimensão interseccional de sexo, raça, etnia e classe. A autora crítica definições ocidentalizadas que usam linguagem etnocêntrica, que falham em construir agência feminina no debate, a questão do racismo nas definições iniciais do século XX, assim como aspectos xenófobos e preconceituosos.

Louise Shelley (2003, p. 119) propõe análise sobre o tráfico a partir de outra perspectiva: o modelo de negócio, ou seja, "as práticas de negócios dos grupos criminosos internacionais que traficam mulheres", de maneira especial, como lucros incorporados e o dinheiro é lavado. Assim, um olhar sobre o modelo permitiria compreender o contexto geral de violação de direitos humanos. A autora considera que o Protocolo de Palermo deixa claro o processo "mercadológico" do tráfico, que envolve finalidade, meios e organização.

Este modelo de negócio opera com a cumplicidade de profissionais nos países de destino que proveem serviços aos contrabandistas e traficantes, criando expertise e organização em redes. O modelo envolve também violência e abusos, além de 
facilitadores especializados no Ocidente, assim como agentes de médio e alto escalão governamentais que desmantelam ou dificultam fiscalização e operações policiais, e investidores da indústria do sexo. Toda essa rede "investe em tecnologia, inteligência e comunicação sofisticada necessária ao crescimento do tráfico e comércio" (Shelley, 2003, p. 122). Não obstante, estas redes e organizações operam em diversos contextos culturais e políticos altamente adaptados às dinâmicas.

Shelley (2003) cria um esquema a partir de seis modelos de negócios, onde analisa os lucros e a lavagem de dinheiro. Quando aos lucros, a operacionalização entre os modelos vai desde o contrabando, tráfico sexual de mulheres, tráfico de drogas, escravidão e até uso de regulação local para explorar indiretamente. Quanto à lavagem de dinheiro, os lucros vão desde consenso da própria organização criminosa, investimentos em bens e imóveis, redirecionamento à outras atividades criminosas, repatriação à comunidade de origem do traficante e até investimentos em negócios legais e regularizados.

Já Desylla (2007) propõe um esquema que considere o contexto de dinâmicas sociais presentes nas migrações, evidenciando dimensões de exploração próprias, dos sistemas sociais que se relacionam com a exploração do tráfico. A autora sinaliza que as vítimas e grupos marginalizados devem falar por si, o que afasta as dimensões de resgate de uma vítima, cuja voz sequer é ouvida. Fundamental, ainda, é construir políticas de apoio às vítimas que não padeçam de estereótipos que revitimizem e construam imagem de coautor do crime, em vez de vítima.

Tatiana Sousa (2016, p. 271) aponta a necessidade de se ter um olhar atento às dimensões socioeconômicas da dinâmica do tráfico de mulheres, considerando que "o contexto que enraíza os problemas sociais vivenciados pelas mulheres em situação de tráfico de pessoas e migração irregular, está relacionado à precarização das relações de trabalho e o fato de políticas estatais efetivas. Neste sentido, a autora inclui existir um contexto de contradições entre as políticas públicas nacionais e sua operacionalização.

Vanessa Munro (2006) considera que políticas de combate ao tráfico sexual sobre inúmeras resistências na sociedade, seja quando assume caráter punitivista ao largo das vítimas do tráfico (pela associação à prostituição), seja pelo contexto defensor de direitos humanos (pela abordagem centrada na vítima). Assim, com um tema não pacificado, sequer em sua conceituação sociológica ou jurídica, o tráfico sexual é controverso politicamente.

\subsection{A pessoa traficada e o status da vítima: um esquema político}

Um fenômeno crítico ao tráfico de mulheres congrega da sua invisibilização à generalização, intermediadas pela dificuldade de um "perfil" descritivo de quais mulheres estariam mais expostas à serem vitimadas por este crime. Desde a falta de denúncias à escassez de dados, o que se percebe parte de representações sociais "constituídas por uma imagem de mulher traficada como aquela que pertence a um grupo socioeconômico pobre [...] a fim de melhorar as suas condições de vida e as de sua família" (Zuquete; Souza; Deslandes, 2016, p. 7). Além deste "perfil" ser pouco representativo, também não há um "perfil" sobre os traficantes, os líderes das organizações criminosas nem os clientes. Neste aspecto, este perfil delimitado pode levar a violações de direitos humanos nos tratos às vítimas, assim como dificulta o entendimento da rede que orienta a indústria do sexo, a qual conta com clientes igualmente negligenciados nestes "perfis".

Analisando especificamente o caso de Israel, Abu e Zarhin (2019, p. 185) analisam que foi ao longo dos anos de 1990 que o país se tornou um dos destinos do tráfico para fins de exploração sexual, a maioria de mulheres oriundas de migração legal, vistas como de "ameaça à saúde pública e portadoras do estigma da prostituição". No caso de Israel houve uma reação de contestação à adoção de normas internacionais. Inicialmente, tem-se um problema de migração ilegal, cujos envolvidos eram todos criminosos, com foco na prevenção e persecução. A partir de feministas liberais, a contestação torna o tráfico orientado à proteção da vítima, seu resgate e reabilitação, além de reintegração. Assim, a concepção de vítima muda politicamente.

Bonny Ling (2018) critica o uso do termo "tráfico de pessoas para fins de exploração sexual" relativo a um sinônimo ao termo "prostituição feminina", por associar todas as mulheres na indústria do sexo como vítimas. Quando a confusão ocorre, 
surgem políticas de combate ao tráfico que tomam a prostituição igualmente como problema a ser combatido com o primeiro. Analisando o caso chinês, a autora observa que a prostituição é derivada do tráfico, sendo todas as mulheres inseridas em propostas políticas de resgate e reabilitação. Ainda, a equiparação da ideia de prostituição como violação, ou seja, em um crime cometido pelas mulheres como partícipes.

Compreender a prostituição como derivada do tráfico, além de não situar a voluntariedade em casos específicos, cria desafios à identificação de redes de organizações criminosas e traficantes por confundir processos, mecanismos de coerção e captura de mulheres, assim como homogeneíza a "vítima" e o cliente neste mercado do sexo. Outro aspecto crítico é o obscurecimento que leva à falta de dados, tendo em vista a confusão entre práticas. Ling (2018) pondera, por exemplo, casos notórios de prostituição forçada via manipulação fraudulenta de mulheres, que não se percebe como tráfico, por envolver o aspecto doméstico.

O mais grave, contudo, está na estigmatização: a prostituição como um crime, torna as vítimas do tráfico e prostituição, criminosas aos olhos da Lei e da sociedade, justamente pela confusão das políticas anti-tráfico com anti-prostituição. A vítima do tráfico, quando confundida, perde seu status de vítima, estando afastadas de concepções de direitos humanos ou de acolhimento, cuidado e reabilitação. Em termos de gênero, diz Ling (2018), demonstra como o processo generificado do tráfico e da prostituição acaba se perdendo, dando lugar às concepções morais, proibitivas e incapazes de compreender a complexidade que envolve tanto o tráfico quanto a prostituição.

Caroline Ausserer (2008) comenta que o contexto das discussões sobre Direitos Humanos, as agendas e pressões sociais fazem da política de combate ao tráfico uma forte questão política em governos, cujo foca reorienta em processos, atores, rotas e exploração. O tráfico é visto como um "mal", em dimensão moralista, onde o sujeito traficado é lido via concepções particularistas pelos atores envolvidos no seu combate. Isso tem implicações políticas sobre agentes, criminosos, vítimas e a sociedade. Em suma, recaem duas visões: a repressiva e a empoderadora, onde a primeira foca nas pessoas traficadas, voltandose contra, e a segunda induz direitos e controle, restaurando suas vidas.

Primeiramente, a linguagem aplicada à concepção da vítima de forma negativa, estrutura remoção da agência de pessoas adultas que sejam vítimas e a infantilização de mulheres, em que, este último, comporta grupo separado sem direitos e status legal. No caso do primeiro aspecto, trata as vítimas como vulneráveis, sem qualquer agência e possibilidade autônoma de defesa de si. Do mesmo modo, esquemas deste tipo "afastam engajamento ativo de vítimas no processo legal, respeitando seus direitos, necessidades e atos em seus interesses" (Weekes, 2006: 30). Estes dois processos são perceptíveis quando leis de combate ao tráfico isolam vítimas forçadamente à espera do processo penal, figurando aspectos protetores que não abrem margem à escolha.

Ella Cockbain e Kate Bowers (2019) destacam o histórico processo de associação entre o lobby abolicionista com movimentos conservadores morais na criação de legislação contra prostituição. As autoras comentam ainda que desde a segunda década do século XXI surgem leis que incidem em territórios físicos e online, delimitando tensões referentes ao entendimento das relações entre prostituição e tráfico. As autoras ainda comentam que o tráfico de pessoas vem sendo tratado em termos absolutos, mas que pertence "espectro ampliado de exploração, coerção e consentimento" (Cockbain; Bowers, 2019, p. 16). Existem diferenças entre as vítimas de distintos tipos de crime de tráfico, sejam características sociodemográficas, experiência do crime e as respostas oficiais. Assim, a especificidade é necessária à compreensão do contexto.

Em seguida, o conjunto dessas leis pode ser vista na África do Sul, que desconsidera o caráter global migratório de pessoas em busca de oportunidades e melhores condições de vida. Assim, um entrave migratório resvala em opção que deriva no tráfico, quando da dificuldade legal migratória. Aponta Weekes (2006: 30) que mulheres vítimas exploradas e trabalhadoras do sexo são "afastadas de criar políticas para elas mesmas". Por fim, a autora ressalta que estas leis não vão a fundo na cadeia da indústria do sexo, mas foca em estabelecimentos. Este último é espelho de contextos abolicionistas da prostituição, que entende todas as prostitutas como vítima a serem salvas. 
Há também o contexto de prostitutas estrangeiras, suspeitas da xenofobia do controle territorial e moralidades das mulheres e homens locais, que evidenciam desrespeito aos direitos humanos. Novamente se reforçam a fragilidade e vulnerabilidade das mulheres, sua capacidade de agência e que todo trabalho sexual seria forçado. Weekes (2006) também aponta que isto associa, igualmente, em termos de classe, que apenas mulheres pobres e ignorantes estariam em contexto mais fragilizado. O Estado, assim, acaba promovendo uma delimitação em que vítimas e trabalhadoras do sexo ou aqueles que tiveram alguma experiência no tráfico de pessoas, não participam da criação de políticas nesta temática.

Leslie Frescura (2006, p. 140) considera "o tráfico de mulheres com fins de exploração sexual como a forma de violência contra a mulher mais difundida e invasiva" e como um claro abuso de direitos humanos que não se limita à violência direta dos agentes agressores, mas, igualmente, um processo em que mulheres sofrem violência de agentes públicos por sua incapacidade em desenvolver ações comprometidas com a sensibilidade e respeito necessários ao reconhecimento do status da vítima às vítimas do referido crime. Assim, o tráfico abusa da vulnerabilidade.

Destaca Singh (2004) que o abuso da vulnerabilidade da pessoa em que se encontrava previamente ao tráfico, continua, sob outras formas pós-tráfico, seja com dívidas, retenção da documentação ou ameaças de caráter migratório. Não obstante, existem as ameaças físicas ou às famílias que vítimas de tráfico recebam, após um processo em que não estejam mais sob domínio físico dos traficantes. Ainda se tem a questão das pendências legais migratórias, as quais aparecem como mais uma ameaça que deve ser eliminada em um processo acolhedor das vítimas do tráfico, afim de que possam cooperar e se sentirem seguras. Portanto, agencia, autonomia e passividade são categorias que fazem parte de políticas de combate ao TIP.

A violação de direitos humanos é uma violação da integridade do indivíduo em múltiplas esferas, como o corpo, o respeito à dignidade, a moral, dentre outros, que demanda processos de reconhecimento que tratem a vítima respeitando seu status, agência e não a colocando em um contexto de passividade e vitimização à espera de um resgate. Como ressaltado por Frescura (2006), reconhecer dinâmicas de empoderamento em que estão sujeitas as vítimas deste processo não é o mesmo que entendê-las como sem qualquer capacidade de agência, estando em situação de passividade, ainda que não mais nas mãos dos traficantes.

Ao comparar ações de combate ao tráfico de mulheres, Goodey (2004, p. 30-31) observa os movimentos de recuperar a centralidade na vítima. O processo tem relação com a remissão aos direitos humanos, que orienta em suas necessidades e direitos, junto à proteção efetiva e persecução de casos de tráfico. A abordagem centrada na vítima ainda coloca a prevenção da vimitização, a persecução de agressores e proteção/assistência às vítimas em legislação nacional e internacional e seus impactos na natureza e extensão do crime. A questão crítica é que estes processos só são pautados quando da cooperação da vítima com as autoridades policiais e judiciais.

No âmbito do tráfico de pessoas, as mulheres padecem de categorias como "outros indesejáveis", "imigrantes ilegais", dentre outras, em seu tratamento como vítimas do crime, o que cria percepções acerca da baixa possibilidade de eliminar o crime pela restrita cooperação. Isto, inclusive, revela para Googey (2004, p. 33) uma centralização masculina dos mecanismos de combate ao tráfico de pessoas para fins sexuais, já que "as mulheres não são priorizadas como vítimas pela justiça criminal", sendo vistas menos como vítimas do que como cúmplices dos crimes envolvidos, dando como naturalizado em consentimento, cuja complexidade sequer é constituída na investigação. Ter a vítima em dimensão central é considerar o reconhecimento do status da vítima a cada indivíduo, por conta de um crime, mantendo e assegurando seus direitos e apoio. Isso se dá, não obstante, nos casos de mulheres imigrantes ilegais. Neste ponto Goodey (2004) distingue a dimensão legal/institucional da identidade da vítima em que se deve considerar o que uma pessoa tenha sofrido este processo demanda de fato.

Neste contexto, a abordagem centrada na vítima vem a considerar: 1) a informação; 2) cuidado e respeito; 3) privacidade e proteção; 4) restituição e/ou compensação; 5) o direito da vítima à fala. Estes cinco aspectos fazem parte de uma série de documentos legais europeus, os quais, para Goodey $(2004$, p. 42) ainda padecem de considerar uma abordagem centrada na 
mulher, "com respeito às experiências particulares e necessidades de vítimas de tráfico sexual como mulheres". Especificamente, considerando como lidar com casos de violência sexual, o exame clínico médico por agentes mulheres especializadas, além de ambiente apropriados às mulheres, distantes de localidades masculinizantes. A articulação de uma abordagem centrada na vítima com uma abordagem centrada na mulher poderia prover melhores condições às vítimas e situar possibilidades de ação de inteligência no combate ao crime.

Goodey (2004) destaca que um dos programas recentes utilizados é o de "proteção da testemunha", o qual envolve crimes de alta intimidação. Quando aplicado às vítimas de tráfico sexual, há a diferença de que geralmente estas não são capazes de prover informações concisas, pelo alto grau de controle à que foram submetidas e também por serem as "commodities" do processo, passadas e repassadas em redes, bordeis e traficantes, não sabendo definir os líderes da organização criminosa. Este desconhecimento implica contexto temoroso à vítima em denunciar ou colaborar, além de efetivamente, a manter em risco de vida. Goodey (2004), por fim, destaca que nenhum programa da União Europeia foi capaz de considerar circunstancias e necessidades das vítimas traficadas.

\section{Considerações Finais}

O Tráfico Internacional de Pessoas é um crime não apenas em seu sentido jurídico ou em sua terminologia legal subscrita em Códigos Penais no mundo. Trata-se de uma violência política que parte de contextos socioeconômicos e políticoinstitucionais, encontrando nos mesmos, os elementos necessários a seu fortalecimento, institucionalização local e ramificação internacional. Igualmente, trata-se de uma violência que fere a integridade humana pela sua destituição dos elementos que caracterizam um ser humano em sua essência, seu corpo, humanidade e respeito. Todavia, é um fenômeno atípico na Teoria Política por conta de sua confusão conceitual no entendimento das questões sociais relativas às dimensões normativas que agendas políticas de combate ao tráfico carregam em suas concepções. É na delimitação das concepções e seu posterior entendimento das lentes que lerão a realidade social, que parte a confusão normativa.

Um elemento legalístico importante deste processo de confusão, é que os mecanismos de combate internacional situariam apenas um limite jurídico e não sociológico deste fenômeno, desconsiderando motivos e contextos de sua criação, manutenção e ampliação como um elemento parte da cadeia de "negócios" que existem em vários países. Por este sentido, é comum que se confunda, jurídica e até sociologicamente, a prostituição com o TIP, os quais, em certa medida, podem ter relações, mas não devem ser confundidos, pois, a sua confusão, pode impedir ações efetivas de combate às concepções de fenômenos distintos, porém próximos. Não obstante, o TIP não é o mesmo em cada país, pelo contrário, seus mecanismos de aliciamento, estruturação das redes e negócios, assim como a exploração propriamente dita, variam conforme condições socioeconômicas e político-institucionais das vítimas e do território em que o tráfico se delimita, mesmo que se trate de um crime transnacional.

Em termos de objeto, o TIP envolve um foco na justiça criminal muito mais reativa do que preventiva, cujo foco é a coerção, e prisão em contexto de transnacional, com pouca abordagem específica quanto às condições de desigualdades sociais que levam as pessoas serem vitimadas pelo tráfico. Uma das indicações desta pouca abordagem recai nas dificuldades que envolvem as práticas culturais como desafio às ações internacionais coordenadas por múltiplas nações, uma vez que, determinadas práticas culturais associadas ao TIP não seriam tipificadas como crimes, tornando a abordagem internacional mais complexa pela relação local/global.

Contudo, ressalte-se que o TIP, como um fenômeno global, atuante em células e ramificado em organizações criminosas que se aproveitam de brechas legais para desenvolver estes "negócios", estruturam o TIP como incapaz de ser enquadrado territorialmente, o que demanda reconfiguração dos mecanismos convencionais de prevenção, proteção e persecução. Para tanto, o TIP deve abordar um contexto que conjugue pactos e convenções do Direito Internacional, como forças de lei, para com as bases jurídicas domésticas dos territórios de origem ou destino do TIP para instauração de sistema de cooperação internacional. 
Ainda, este processo precisa ser parte de uma Agenda Política internacional com caráter doméstico, que agregue as duas dimensões como conciliáveis e não concorrenciais por disputas que envolvem fronteiras, mercados e processos.

Delimitamos três esquemas analíticos:

1. Com o esquema conceitual, há de se delimitar o tráfico afim de tornar sua conceituação mais precisa e menos confusa quanto aos crimes correlatos, implicando a caracterização do crime e possibilidade de aplicar mecanismos de prevenção, proteção e persecução;

2. Com o esquema sociológico-jurídico, deve-se considerar como o tráfico não apenas parte, mas se conjuga com as dinâmicas sociais da localidade, das pessoas, das instituições políticas e legais, em termos de que é um crime plástico em sua manifestação, capaz de se articular às dinâmicas sociais;

3. Com o esquema político, é fundamental considerar como a vítima é percebida em seu status civil, político e jurídico, considerando como a Cidadania, os Direitos Humanos e sua Integridade se articulam com os mecanismos de combate ao tráfico, no sentido de que a vítima não deve ser revitimizada e deve ser um sujeito de direitos pleno.

Não obstante, os três esquemas podem permitir, em conjunto, uma leitura mais precisa de um crime que não pode mais ser lido sob apenas uma lente. Por fim, esperamos que as indicações analíticas elaboradas neste texto, possam permitir estudos aprofundados, especialmente em termos de incorporação dos tratados internacionais e legislações criminais. Indicamos como limite do trabalho o fato de que estes esquemas precisam ser reduzidos sociologicamente às condições dos locais a serem analisados, notadamente, quando associadas às legislações. Também destacamos que são necessárias análises a partir de vulnerabilidades sociais e seus impactos, uma vez que os esquemas se propõe a analisar estas vulnerabilidades.

\section{Agradecimentos}

$\mathrm{O}$ autor agrade aos pareceristas pelas contribuições ao artigo. Este trabalhou contou com financiamento em bolsas de pesquisa do Conselho Nacional de Desenvolvimento Científico e Tecnológico (CNPq) e da Fundação de Amparo à Pesquisa do Estado do Rio de Janeiro (Faperj).

\section{Referências}

Abu, Ofir, \& Zarhin, D. (2019) Between Universal Human Rights and Ethno-National Values: Israel's Contested Adoption of the Global Anti-Trafficking Norm. Israel Studies, 24(3), 180-203. www.jstor.org/stable/10.2979/israelstudies.24.3.08.

Anwary, A. (2007). Anti-Sex Trafficking Movement of Bangladesh and the Theories of Transnational Social Movements. Social Thought \& Research, 28, 109142. www.jstor.org/stable/23252123.

Ausserer, C. (2008). 'Control in the Name of Protection': A Critical Analysis of the Discourse of International Human Trafficking as a Form of Forced Migration. St Antony's International Review, 4(1), 96-114. www.jstor.org/stable/26225808.

Baptista, V. F. Das lógicas em disputa no direito a ter direito no contexto das medidas protetivas. Revista Eletrônica Espaço Acadêmico (Online), 20, 174-187, 2020a. http://periodicos.uem.br/ojs/index.php/EspacoAcademico/article/view/53430

Baptista, V. F. The critique of justice in the debate between Nancy Fraser and Axel Honneth: notes toward a critical theory. Revista Argentina de Ciencia Política, 1(25), 37-62, 2020b. http://https//publicaciones.sociales.uba.ar/index.php/revistaargentinacienciapolitica/article/view/6141

Baptista, V. F. Violência contra à mulher e perspectivas de ações programáticas: o sentido estrutural da violência direta e indireta. Revista do Núcleo de Estudos e Pesquisas em Gênero \& Direito (UFPB), 8, 214-236, 2019. http://https//periodicos.ufpb.br/ojs/index.php/ged/article/view/47763

Cabezas, A. (2016). Invisible Dominican Women: Discourses of Trafficking into Puerto Rico. Cadernos Pagu, 47, 1-33, e16477. http://www.scielo.br/scielo.php?script=sci_arttext\&pid=S0104-83332016000200402\&lng=en\&nrm=iso.

Cockbain, E., \& Bowers, K. (2019). Human trafficking for sex, labour and domestic servitude: how do key trafficking types compare and what are their predictors?. Crime, Law and Social Change, 72, 9-34. Recuperado de https://link.springer.com/article/10.1007/s10611-019-09836-7.

Charlesworth, H. (2000). Martha Nussbaum's Feminist Internationalism. Ethics, 111(1), 64-78. www.jstor.org/stable/10.1086/233419. 
Cho, S. Y. (2012). Integrating Equality: Globalization, Women's Rights, and Human Trafficking. International Studies Quarterly, 57(4), 683-697. www.jstor.org/stable/24014642.

Choi, E. (2014). North Korean Women's Narratives of Migration: Challenging Hegemonic Discourses of Trafficking and Geopolitics. Annals of the Association of American Geographers, 104(2), 271-279. www.jstor.org/stable/24537719.

Desyllas, M. C. (2007). A Critique of the Global Trafficking Discourse and U.S. Policy. The Journal of Sociology \& Social Welfare, 34(4), 57-80. https://scholarworks.wmich.edu/jssw/vol34/iss4/4.

Farrell, A., \& Pfeffer, R. (2014). Policing Human Trafficking: Cultural Blinders and Organizational Barriers. The Annals of the American Academy of Political and Social Science, 653, 46-64. www.jstor.org/stable/24541774.

Freire, S. M. V. (2017). Tráfico Internacional de Pessoas e Cooperação Internacional: Um Olhar no Brasil. Lumen Juris, 2017.

Frescura, L. (2006). 'There Is No Escape from That Miserable Life'. Agenda: Empowering Women for Gender Equity, 70, 139-144. www.jstor.org/stable/4066749.

Ghosh, B. (2014). Vulnerability, Forced Migration and Trafficking in Children and Women: A Field View from the Plantation Industry in West Bengal. Economic and Political Weekly, 49(26/27), 58-65. www.jstor.org/stable/24480169.

Goodey, J. (2004). Sex Trafficking in Women from Central and East European Countries: Promoting a 'Victim-Centred' and 'Woman-Centred' Approach to Criminal Justice Intervention, Feminist Review, 6, 26-45, 2004. www.jstor.org/stable/1395927.

Lansink, A. (2006). Human Rights Focus on Trafficked Women: An International Law and Feminist Perspective. Agenda: Empowering Women for Gender Equity, 70, 45-56. JSTOR, www.jstor.org/stable/4066725.

Ling, B. (2018). Prostitution and Female Trafficking in China: Between Phenomena and Discourse. China Perspectives, 113(1-2), 65-74. www.jstor.org/stable/26531913.

Meshkovska, B. et al. (2015). Female Sex Trafficking: Conceptual Issues, Current Debates, and Future Directions, The Journal of Sex Research, 52(4), 380-395. https://www.tandfonline.com/doi/abs/10.1080/00224499.2014.1002126.

Ministério da Justiça. (2017). Relatório Nacional sobre o Tráfico de Pessoas: Dados 2014 a 2016. Brasília, Ministério da Justiça. $\langle$ https://www.justica.gov.br/sua-protecao/trafico-de-pessoas/publicacoes/relatorio-de-dados.pdf>.

Munro, V. E. (2006). Stopping Traffic? A Comparative Study of Responses to the Trafficking in Women for Prostitution. The British Journal of Criminology, 46(2), 318-333. www.jstor.org/stable/23639379.

Ne, F. Y. (2018). Human Trafficking: In the Shadows of the Law. S. Rajaratnam School of International Studies, 1-10. www.jstor.org/stable/resrep26880.

Nucci, G. S. (2015). Prostituição, Lenocínio e Tráfico de Pessoas: Aspectos Constitucionais e Penais. (2a ed.), Forense.

Parliament of the United Kingdom. (1885). Criminal Law Amendment Act 1885. http://www.irishstatutebook.ie/eli/1885/act/69/enacted/en/print.

Pereira, A. S. et al. (2018). Metodologia da pesquisa científica. Ed. UAB/NTE/UFSM. https://repositorio.ufsm.br/bitstream/handle/1/15824/ Lic_Computacao_Metodologia-Pesquisa-Cientifica.pdf?sequence=1

Petersen, K. L. (2001). Trafficking in Women: The Danish Construction of Baltic Prostitution. Cooperation and Conflict, 36(2), 213-238. www.jstor.org/stable/45084008.

Rodrigues, T. C. Tráfico Internacional de Pessoas para Exploração Sexual. Saraiva, 2013.

Santos, B. S., Gomes, C., \& Duarte, M. (2010). The Sexual Trafficking of Women: Representations of Illegality and Victimisation, Revista Crítica de Ciênciais Sociais Annual Review [Online], 2, 167-191. http://journals.openedition.org/rccsar/247.

Sharapov, K. (2017). Traffickers and Their Victims: Anti-Trafficking Policy in the United Kingdom. Critical Sociology, 43(1), 91-111. https://doi.org/10.1177/0896920515598562.

Shelley, L. (2003). Trafficking in Women: The Business Model Approach. The Brown Journal of World Affairs, (1), 119-131. www.jstor.org/stable/24590598.

Singh, D. Piercing the veil on trafficking in women. (2004). The Comparative and International Law Journal of Southern Africa, 37(3), $340-363$. www.jstor.org/stable/23252164.

Smith, A. S. P. O. Tráfico de Pessoas para Exploração Sexual. Lumen Juris, 2017.

Secretaria Nacional de Justiça. (2013). Tráfico de Pessoas: uma Abordagem para os Direitos Humanos. 1. ed. Brasília: Ministério da Justiça, 2013. https://www.justica.gov.br/sua-protecao/trafico-de-pessoas/publicacoes/anexos/cartilha_traficodepessoas_uma_abordadem_direitos_humanos.pdf

Sousa, T. R. (2016). Tráfico de mulheres e exploração sexual: análise sobre o atendimento às vítimas. Revista Katálysis, 19(2), 270-280. http://www.scielo.br/scielo.php?script=sci_arttext\&pid=S1414-49802016000200270\&lng=en\&nrm=iso

Stoyanova, V. (2017). The Relationship between the Concept of Human Trafficking and the Concepts of Slavery, Servitude and Forced Labour. In: Human Trafficking and Slavery Reconsidered: Conceptual Limits and States' Positive Obligations in European Law. Cambridge: Cambridge University Press, p. 292$318,2017.10 .1017 / 9781316677070.007$

Swanson, J. (2016). Sexual liberation or violence against women? The debate on the legalization of prostitution and the relationship to human trafficking. New Criminal Law Review: An International and Interdisciplinary Journal, 19(4), 592-639. www.jstor.org/stable/26417715. 
Research, Society and Development, v. 10, n. 1, e42110111993, 2021

(CC BY 4.0) | ISSN 2525-3409 | DOI: http://dx.doi.org/10.33448/rsd-v10i1.11993

United Nations. (1921). International Convention for the Suppression of the Traffic in Women and Children. Geneva, 30 September 1921. https://treaties.un.org/Pages/ViewDetails.aspx?src=TREATY\&mtdsg_no=VII-3\&chapter=7\&clang=_en

United Nations. (1933). International Convention for the Suppression of the Traffic in Women of Full Age. Geneva, 11 October 1933. https://treaties.un.org/Pages/ViewDetails.aspx?src=TREATY\&mtdsg_no=VII-5\&chapter=7\&clang=_en

United Nations. (1904). International Agreement for the Suppression of the White Slave Traffic, signed at Paris on 18 May 1904, amended by the Protocol signed at Lake Success, New York, 4 May 1949. https://treaties.un.org/doc/Treaties/1951/06/19510621\%2010-34\%20PM/Ch_VII_7p.pdf

United Nations Office on Drugs and Crime. (2018). Relatório Global sobre Tráfico de Pessoas - Perfil do País da América do Sul. United Nations: New York. https://www.unodc.org/documents/lpo-brazil//Topics_TIP/Publicacoes/2018_GloTiP_South_America.pdf.

United Nations Office on Drugs and Crime. United Nations Convention Against Transnational Organized Crime and The Protocols Thereto. United Nations: New York, 2004.https://www.unodc.org/documents/treaties/UNTOC/Publications/TOC\%20Convention/TOCebook-e.pdf

Van Dijck, M. (2005). Trafficking in Human Beings: a Literature Survey. Tilburg, Netherlands: Tilburg University.

Venson, A. M., \& Pedro, J. M. (2013). Tráfico de pessoas: uma história do conceito. Revista Brasileira de História, 33(65), 61-83. <http://www.scielo.br/scielo.php?script=sci_arttext\&pid=S0102-01882013000100003\&lng=en\&nrm=iso>.

Watson, J., Silkstone, C. (2006). Human Trafficking as a Form of Gender-Based Violence: Protecting the Victim. Agenda: Empowering Women for Gender Equity, 70, 110-118. www.jstor.org/stable/4066741.

Weekes, A. (2006). South African Anti-Trafficking Legislation: A Critique of Control over Women's Freedom of Movement and Sexuality. Agenda: Empowering Women for Gender Equity, 70, 29-37. www.jstor.org/stable/4066723.

Zuquete, J. G. Pais E. S., Souza, E. R., \& Deslandes, S. F. (2016). Concepções sobre o tráfico de mulheres para fins de exploração sexual: um estudo com representantes institucionais no Brasil e em Portugal. Cadernos de Saúde Pública, Rio de Janeiro, 32(10), 1-11, e00075415. http://www.scielo.br/scielo.php?script=sci_arttext\&pid=S0102-311X2016001005003\&lng=en\&nrm=iso 